\title{
Towards the development of a comprehensive systematic quantification of the costs and benefits of property level flood risk adaptation
}

\author{
R. Joseph ${ }^{1,2}$, D. G. Proverbs ${ }^{1}$, J. Lamond ${ }^{1} \&$ P. Wassell ${ }^{2}$ \\ ${ }^{I}$ Faculty of Environment and Technology, \\ University of the West of England, Bristol, UK \\ ${ }^{2}$ Cunningham Lindsey, UK
}

\begin{abstract}
Research in the UK, has shown that one of the reasons that people may not take action to guard against potential flood damage to their properties is that they lack first-hand information on the costs and benefits of available mitigation measures. From these perspective, fundamental issues of both universal and constraint uncertainties in property-level flood adaptation cost benefit analysis are discussed. Individuals who have direct knowledge of the potential flood risks that they are exposed to and subsequently have information on the costs and benefits of adapting their properties to flood risks, would be more likely to take action, and thus more inclined to undertake mitigation measures. The application of the concept of cost benefit analysis to flood mitigation measures at household levels has inherent uncertainties. A major exclusion in the past from flood mitigation cost benefit analyses has been the intangible impacts of flooding upon households, and this represents a form of systemic uncertainty. Research has shown that intangible impacts are both large and more important to affected households than are the tangible impacts; therefore quantification of the intangible impacts of flooding, for the purpose of developing a comprehensive cost benefit analysis model, is of a paramount importance in assessing the full impact of flooding on households, and hence currently represent a form of systematic uncertainty. The challenge of this research is how to quantify intangible impact/losses in the context of the cost benefit analysis approach.
\end{abstract}


A proposal for addressing this challenge is presented which could help homeowners living in flood risk areas in the UK to make an informed decision on investment in flood mitigating measures.

Keywords: cost-benefit analysis, choice modelling, contingent valuation, intangible impacts, property-level flood adaptation.

\section{Introduction}

It has been recognised, both at the European level and in the UK that there is a need for a shift from defensive action against flood risk to better management of flood risk. Flood risk management in the UK has, therefore, undergone a series of radical reviews (Institution of Civil Engineers Learning to Live with Rivers, 2001); DEFRA Making Space for Water (2005) and the Foresight Project Future Flooding (Evan et al. [1]) which have proposed less reliance on hard engineering solutions such as flood defence. Evans et al [1] stressed the need for a concept shift in which flood risk management relies less on Government intervention and more on an acceptance of individual responsibility. Concurring with this, the Environment Minister Richard Benyon said "Government has a role to play in managing the overall risk to the nation, but we all, as individuals need to take greater responsibility for understanding our own flood risk and minimising it where we can". In general, the most visible and obvious impact of floods upon households is the physical damage to contents and the fabric of the building [2] this is known as the tangible losses / impacts. These are damages, which can be easily specified in monetary terms [3].

This tangible damage is conventionally assessed in terms of such variables of flood characteristics such as depth and duration; land use patterns and the area's susceptibility to flood damage [4]. This conventional approach only takes into consideration the tangible damage, the consequences of which are that decisions are made with incomplete information in that intangible losses/impacts (for example impacts on health and general well being) are not considered. A further complication for UK householders in determining whether to invest in property level flood risk adaptation measures is that the bulk of reinstatement costs are currently borne by insurance companies for those homeowners who are fully insured $[5,6]$. Insurance enables property owners to minimise the financial cost of damage from flooding but it cannot remove the trauma and misery of the experience.

Due to availability of insurance provision in the UK, some homeowners may have become complacent and have no reason to think of investing their limited resources in property-level flood adaptation measures, since it is believed that by paying their premium, they have successfully transferred the risk to the insurer. Although insurance can and does play a positive role, it may be more beneficial for property owners to reduce the effects of flooding as much as possible in the first place by protecting their homes from flood damage. This is because insurance provision only covers the tangible losses / impacts suffered by homeowners whereas the intangible looses / impacts are borne by homeowners as they are not insurable. Investment in property level flood adaptation measures 
have the potential to reduce some of the intangible losses / impacts which research has shown to be more devastating than the tangible losses / impacts [7]. As noted above, exclusion of intangible losses leads to a biased cost assessment of flood impacts/losses, and then an optimised allocation and design of damage reduction measures cannot be ensured. Hence, for a fully integrated assessment and management of flood risks it would be necessary to consider both the tangible and intangible impacts and their costs so as to incorporate these within the cost benefit analysis decision making tool.

Cost benefits analysis (CBA) is a widely accepted and often used tool for decision-making. CBA is an analytical tool based in welfare theory, which is conducted by aggregating the total costs and benefits of a project or policy over both space and time [8,9]. To date there has been a dearth of research that investigates the possibility of applying the concept of cost benefit analysis to property level flood adaptation measures; this is due to difficulties involved in the process of monetising intangible impacts. One of the ways in which intangible costs could be included in the CBA decision making tool is to find a technique whereby intangible impacts/looses can be monetised so as to fit within the CBA decision making tool; this is one of the challenges of this research work.

It is against this backdrop, that a review and evaluation of the methods for quantifying the intangible impacts of flooding on households is hereby presented. Further, the context in which each of these methods can be used and their respective weaknesses are also explained. This aims at compiling and analysing the methods for the quantification of the intangible impacts/losses as well as to provide recommendations towards an effective application and subsequent incorporation of the intangible impacts in the CBA decision making tool at household property-level.

\section{Methods of quantifying intangible impacts of flooding on households}

Quantifying the cost of intangible impacts of flooding follows the main principles of welfare and environmental economics. The central themes in the field of welfare economics are to consider all categories of total economic value, including those generated by physical damages to properties and impacts on human health in decision-making. The conventional approach to flood damage mitigating measures takes into consideration only the tangible impacts; this is a determination that is considered to be insufficient for any sound decision-making by homeowners when considering investing in property-level flood adaptation measures. This in turn makes it important to quantify the intangible impact of flooding thereby increasing the accuracy of the assessment of the impact of flooding on households. To evaluate the role of the intangible damage component, there are economic valuation methods which are recognised as suitable to arrive at monetary estimates of non-monetary goods and therefore can be used to estimate the intangible impact of flooding on households. The most commonly used economic valuation methods are known as stated preference 
methods (SPM) and revealed preference methods (RPM) [9], both of which are considered below.

\subsection{Stated preference method of quantifying intangible impact of flooding}

Stated preference methods (SPM), also called direct valuation methods or inferential methods [9], have been developed to solve the problem of valuing intangible impacts/losses that have no obvious market value [10]. The SPMs use statistical techniques to infer the value of something that does not have an observable price [9]. They are survey or experiment-based approaches that elicit people's preference directly. There are two methods of stated preference techniques: contingent valuation method (CVM) and choice modelling method (CMM). Both methods use similarly structured questionnaires but differ in the way they define the non-market effect of concern. In addition to their ability to estimate user costs / values of any environmental impact on people, the most important feature of these survey-based methods is that they can be used to infer the value of intangible impacts/losses on households, thereby enabling the incorporation of the cost associated with intangible impacts within the CBA decision making tool.

\subsubsection{Contingent valuation method (CVM)}

Contingent valuation is a method of estimating the value that a person places on a good or service. Rather than inferring from observed behaviours in regular market places, the approach asks people to directly report their willingness to pay (WTP) to obtain a specified good or service, or willingness to accept (WTA) to give up a good or service. In the context of flooding; CVM depends upon a hypothetical situation or scenario whereby samples of flood plain residents are interviewed and individuals are asked to state their maximum willingness to pay (WTP) in order to reduce or eliminate the intangible impacts of flooding on their households. CVM is a social survey approach; therefore it is very important to pay special attention to the design and implementation of the survey questions and sample design [11].

The pre-requisites to using CVM in estimating the financial value of the intangible impacts of flooding on households are, individual survey of flooded residents, consultations with relevant experts, and pre-testing of the survey questionnaires [12]. Further, decisions need to be taken regarding how to conduct the interviews such as in-person, via mail or via telephone surveys. If the sample can be shown to be representative of the flooded residents population, the mean WTP that have been obtained from the sample can then be extrapolated across the population to obtain the combined WTP $[11,13]$.

The major strength of the CVM is that respondents are given the opportunity to state what they are willing to pay or what compensation they are willing to accept in order to reduce or eliminate the intangible impacts of flooding. Therefore if conducted appropriately the CVM will arrive at a measurement of equivalent financial value that is unambiguous and pertains only to the intangibles. 


\subsubsection{Weakness and bias of CVM}

The possibility of strategic bias was a main objection to the use of CVM in quantifying intangible impacts among most economists. There are two forms of strategic behaviour, namely, free riding and over pledging [11]. Free riding would occur if an individual understates her true WTP for a public good on the expectation that others would pay enough for that good, and therefore, he/she need not have to pay. E.g, a rational response to the current flood risk management policy might be a tendency for respondents to understate the WTP in expectation that this will limit their future liability to contribute towards defence spending. Conversely, in evaluating individual property level measures which is not a public good, respondents may understate their WTP on the prospect that insurance company or government will pay for it. On the other hand, over pledging occurs when an individual assumes that their stated WTP value would influence the provision of good under question, provided that the stated WTP would not form any basis for the future pricing policy. For example, the situation in the past when decisions to build a flood defence from the public purse may have been based on the findings.

One of the weaknesses of using the contingent valuation method in the domain of property level measures is that questions are often problematic, as there is a lot of emotion involved in the answers to these questions because some of the questions may bring back the memory of the flood event(s). However a well designed questionnaire should be able to address this weakness. It is recognised that the WTP by individual is subject to their disposable income as there are income differential among the flood plain residents, this is another inherent bias towards the preferences of the better off. In order to address these drawbacks, a careful survey design is needed for income, age, and ethnicity.

\subsubsection{Application of CVM in the UK}

The most recent and noteworthy application of CVM to health related impact of flooding on households in the UK is the Appraisal of Human Related Intangible Impacts of Flooding, research which was jointly commissioned by Environment Agency and DEFRA (2004). The results demonstrate that flooding causes shortterm physical effects and, more significantly, short and long-term psychological effects. More than $60 \%$ of flooded and at risk respondents expressed a willingness-to-pay (WTP) to avoid the health impacts associated with flooding. Based on the analysis of the survey, the authors recommended that the value of $£ 200$ per household per year be taken as representing the benefits of reduced health impacts as a consequence of a significant reduction in the risk of flooding.

While this can be seen as a move in a positive direction with regards to the quantification of intangible flood impacts on households, the value of $£ 200$ appears to be unrealistic if this is compared to the value of tangible impacts. For example, Green and Penning-Rowsell [14] carried out experimental work by using a bootstrapping procedure to relate known tangible losses to intangible losses by deriving equivalent values. This method was based upon an extensive interview survey with flood victims. In conducting the interview, affected households were asked about the nature of the flood which they have 
experienced, what effects it had and how much it cost to repair or replace the damage, most importantly the respondent were asked if they recovered all their costs from insurances and other sources. The study found that the monetary equivalents of the intangible impacts far exceeded the tangible impacts. Further, Adamson [15] indicated in his report that the intangible impacts are currently set as equivalent to the residential property damage in the evaluation of potential flood damage in the Republic of Ireland.

\subsubsection{Choice modelling method (CMM)}

Choice modelling is concerned with the individual attributes of, say, a flood and estimates WTP for these individual attributes. This method assumes that each respondent has a perfect discrimination capability, whereas the analyst has incomplete information and must therefore take account of uncertainty [10]. The respondents are presented with different bundles of flood impacts which can be reduced by implementation of property level flood alleviation measures at a certain price among which they are asked to make a choice. One of the characteristics of choice modelling methods is a price, and this enables the analyst to infer willingness to pay without asking directly what it is [16].

Similar to contingent valuation method, the cost modelling method can estimate financial values for any environmental resource, and can be used to estimate tangible as well as intangible values. CMM however, enables estimation not only of the value of the environmental resource as a whole, but also of the inherent value of its attributes, their implied ranking and the value of changing more than one attribute at once $[17,18]$. There are a number of variants to choice modelling which differ in the way they present the respondent with the choice task. Only two of these comply with the requirements of economic theory: choice experiments and contingent ranking. Choice experiments require the respondents to choose their most preferred scenario. Contingent ranking requires the respondents to rank the given scenarios according to their preference.

\subsubsection{Application of CMM in the UK}

In the study of the Appraisal of Human Related Intangible Impacts of Flooding in the UK which was jointly commissioned by the Environment Agency and DEFRA, the choice modelling method was used to estimate how much people are willing to pay for a marginal improvement in each attribute of a flood and to estimate how much people are willing to pay to avoid a given flood so long as this flood is within the range of scenarios presented to the respondent. One of the attributes was always price or cost so that WTP was inferred through econometric analysis of trade offs people make between other attributes and cost.

\subsubsection{Choice modelling versus contingent valuation methods}

CMM has become more popular due to several advantages over CVM. These include; the ease of estimating values of single attributes of a flood impact on households; avoidance of part-whole bias problem since different levels of the impacts can easily be built into the experimental design; respondents are more familiar with making choices rather than generating spontaneous valuations. Moreover, CMM can solve some of the biases that are present in CVM; the 
strategic bias which is associated with CVM is minimised in the CMM since the prices of the different intangible flood impacts are already defined in the choice sets. However, the choice approach does limit the valuation to predefined options and does not allow for the respondent to state a zero value for the resource even if they do not value it, however, in order to eliminate the limitation, no change no expense can be an option within the choice set.

\subsection{Revealed preference method of quantifying intangible impact of flooding}

Revealed preference methods, also known as indirect valuation methods, look for related or substitute markets in which the environmental good is implicitly traded. Information derived from observed behaviour in the substitute markets is used to estimate willingness to pay (WTP), which represents individual's valuation of, or the benefits derived from, the investment in flood protection measures [9]. The revealed preference methods have the advantage of producing estimates of the value for a particular good from actual market behaviour; however, care must be taken in extrapolation to market conditions which have not been observed in practice. The two most popular such methods prevalent in the environmental economics literature are the hedonic pricing and the travel cost methods $[3,5,9,10]$. In the context of quantifying the intangible impacts / looses of flooding on household, only the hedonic pricing methods will be considered, because travel cost methods are based on observed behaviour, it is used to estimate use values only.

\subsubsection{Hedonic pricing method}

The hedonic pricing method is intended to determine the influence of the area's characteristics in question, such as a sea view, on the market price of the land or more usually, houses. At the most basic level, a hedonic property value model is based on the premise that it is possible to establish a statistical relationship between a home's sale price and its characteristic. The assumption of the technique of hedonic price is based on the assumption that goods are valued on the basis of a utility provided by their own characteristics. They can be revealed by an observation of property's market prices in relation with the amount observed by attributed characteristics of each property. Macdonald et al [19] carried out a study linking flood risk insurance and the land market to the hedonic price method. They evaluated the consumers' willingness to pay after a reduction of floods occurrence probability. In their models, the hedonic prices are the implicit prices of attributes, such as projects to reduce the flood risk and insurance.

\subsubsection{Application of hedonic pricing methods}

In the studying of the effect of floodplain disclosure in California, Troy and Romm [20] built a multi-layered hedonic regression model containing 27 to 30 significant independent variables including flood status variables, property characteristics such as number of bedrooms, locational characteristics such as coastal location and socio-economic variables such as median household income. 
Hedonic method was applied in Schleswig Holstein (Germany) to derive estimates of the value people attach to different coastal attributes that are at stake if flood events increase as a result of climate change [21]. In Glasgow studying the effects of noise pollution on house value, Day [22] included 31 significant variables including property characteristics, locational characteristics and amenity variables such as views from the property. Lamond et al [23], recognised that it is apparent that to explain adequately the variation in house price between one property and another a great variety of causal variables are needed, and equally that large numbers of observations are necessary to estimate such complex models with any degree of confidence.

There are inherent problems in using the revealed preference methods in quantification of intangibles; the first problem is that the method will measure the flood risk effect as a whole and it is practically impossible to identify what is being taken into account. In order to value intangible in isolation, there will be a need to have some households which experienced intangible losses but no tangible ones and the properties which such household occupied would need to be known, identifying such households may posses problem. The second problem is that of information asymmetry which, arguably, is one of the reasons that no impact is measurable in the long term UK property market.

\section{Incorporation of monetary value of intangible impacts/losses in CBA decision making tool at property level}

The application of CBA to real world problems is not always easy. In quantifying the change in an individual's utility as a result of a flood, two strategies can be used. One, a global or holistic assessment of the change and two, a piecemeal approach of identifying, measuring and quantifying every impact of the flood upon individual or households [14]. The second approach is normally adopted in cost benefit analysis (CBA) approach on flood mitigation measures in the UK.

The aim of CBA is to determine whether a project is desirable from the point of view of social welfare, by means of the algebraic sum of the time-discounted financial costs and benefits of the project. The economic efficiency of the project with long-run-accruing costs and benefits is often assessed using the net present value (NPV) rule. In the context of applying the CBA to property-level flood adaptation measure, there is a requirement that all impacts are taken into account. However, in the analysis of the costs and benefits of flood alleviation measures in practice, the analysis is often narrowed to the consideration of tangible monetary impacts. For example Joseph et al [24] established the cost effectiveness of resilient reinstatement, the result of the analysis indicates that resilient reinstatement is cost beneficial to floodplain resident with 5-25 years flood frequency, this conclusion was reached by considering tangible impacts of flooding. It can be inferred that, if intangible impact was included within the analysis, there is the possibility that the adoption of resilient reinstatement would be economical for properties within a floodplain area of up to 50 years flood 
frequency. The application of CBA to property-level measures means that both costs and benefits need to be broken down in a very detailed way and this means that revealed preference technique is not appropriate because it cannot be broken down.

The practicality of quantification of all costs and benefits is still posing problems in the context of flood protection at an individual property level. Therefore any step towards making the quantification possible makes the comparison and decision more robust. Yet, there is no generally accepted framework available when considering application of the concept of CBA at property-level, where the relevant pieces of information are put together, and there are different ways of monetising the non-monetary impacts. To quantify the intangible impact of flooding on households in pursuit of a comprehensive CBA process for adopting property-level flood adaptation is to use stated preference method of environmental valuation as discussed in sections 2 and 3 above.

\subsection{The use of a CBA tool at household level}

Presently, there is no evidence to suggest that floodplain residents will willingly embrace responsibility for protecting their properties against flood risk because it is not in their financial interest to do so [25]. However, despite their limitations and criticisms, a cost benefit analysis tool could provide detailed property specific information to the homeowner when considering adopting property-level flood adaptation measures. The CBA tool could be used by homeowners during post flood recovery periods when reinstatement work is about to be carried out or during a planned renovation work. Further there is a potential for the CBA tool to be used in non-flood situations and for new build. There is consensus within the literature that implementing resilient or resistance measures during planned renovation work is cost effective $[6,26]$.

The development of a CBA tool for flood mitigation measures could be a useful decision-making tool for homeowners considering to adapt their property to flood risk. For some homeowners, cost will be an absolute barrier. The margin between their basic living costs and their income will not allow them to invest monies on property-level measures. However, with a well structured CBA tool which incorporates all flood impacts on households, there is a possibility of lenders recognising the cost and benefits of the adoption of property-level flood adaptation measures, thereby being willing to offer loans to cover the cost of property-level measures. For homeowners who can afford to invest in propertylevel measures, the CBA tool could help decide which adaptation solution is most effective on a CBA basis. The CBA tool which incorporates both impacts of flooding (tangible and intangible) can be extended to commercial properties, while this review is based on UK experience, the result of the review can have international application, while the building characteristics may be different from country to country, most of the intangible impacts are expected to have similarity from region to region, thereby making the international application of the full CBA tool possible. 


\section{Conclusions}

So far, the conventional approach has not paid much attention to the possibility of quantifying intangible impacts of flooding on households with the intention of incorporating this in the CBA tool for decision making on investment in property-level flood measures. The results of this theoretical review will lead to improved methods for evaluating the intangible impacts of flood on households. The incorporation of the full impact of flooding in the CBA decision making tool at property-level has the potential to lead to a greater understanding of the full costs and benefits of property-level flood mitigation measures by different stakeholders, (i.e. homeowners, lenders and possibly insurance companies). Thereby helping homeowners in decision making on the appropriate adaptation solution which is most effective to their property and situations on a CBA basis. Two methods of valuations of intangible impact of flooding on households were identified in this review, stated preference method (SPM) and revealed preference methods (RPM). The stated preference methods (SPM) are seen to be more suitable than the revealed preference methods (RPM), for monetising intangible impacts of flooding on households. The SPM has their weaknesses and limitations. However the use of SPM valuation methods in eliciting the cost of intangible impacts on households enhances the ability to incorporate common monetary unit within a sound theoretical basis of CBA.

Finally, it has been identified theoretically the importance and methods of monetising intangible impacts of flooding on households and the benefits of incorporating this in the CBA decision making tool at property-level. Further research which will apply the valuation method identified in this review to a real life flood event and subsequent incorporating the monetised intangible impacts into the CBA decision making tool at household property-level is proposed.

\section{References}

[1] Evans, E. P., Ashley, R., Hall, J., Penning-Rowsell, E., Sayers, P., Thorne, C. R. and Watkinson, A. Foresight. Future Flooding, 1 and 2 London. 2004.

[2] Joseph, R., Proverbs, D., Lamond, J. and Wassell, P. A critical synthesis of the tangible impacts of flooding on households. 27th ARCOM annual conference 5-7th September 2011. University of the West of England, Bristol, UK. 2011(c)

[3] Markantonis, V. and Meyer, V. Valuating the intangible effects of natural hazards: a Review and evaluation of the cost-assessment methods. European Society for Ecological Economics conference. Istanbul 14-17 June. 2011.

[4] Lekuthai, A. and Vongvisessomjai, S. Intangible Flood Damage Quantification. Water Resources Management, 15(5), pp. 343-362. 2001.

[5] Lamond, J. E. The impact of flooding on the value of residential property in the UK. Doctor of Philosophy (PhD). Thesis, University of Wolverhampton. 2008. 
[6] Wassell, P., Ayton-Robinson, R., Robinson, D., Joseph, R., Hack, K., Butler, D., Salkeld, I. and Twomey, J. Resilient Reinstatement: The costs of flood resilient reinstatement of domestic properties. Association of British Insurers. 2009.

[7] Joseph, R., Proverbs, D., Lamond, J. and Wassell, P. A critical synthesis of the intangible impacts of flooding on households. International conference in building resilience: Interdisciplinary approaches to disaster risk reduction and the development of sustainable communities. Sri Lanka. 2011.

[8] Hanley, N. and Spash, C. Cost benefit analysis and the environment. England: Edward Elgar Publishing. 1995.

[9] Penning-Rowsell, E., Johnson, C., Tunstall, S., Tapsell, S., Morris, J., Chatterton, J. and Green, C. The benefits of flood and coastal risk management: A manual of assessment techniques. Flood Hazard Research Centre: Middlesex University Press. 2005.

[10] Birol, E., Karousakis, K. and Koundouri, P. Using economic valuation techniques to inform water resources management: A survey and critical appraisal of available techniques and an application. Science of The Total Environment, 365(1-3), pp. 105-122. 2006.

[11] Mitchell, R. C. and Carson, R. T. Using surveys to value public goods: the contingent valuation method. Baltimore: Johns Hopkins University Press. 1989.

[12] Hanemann, M. Valuing the environment through contingent valuation. Journal of economic perspectives, 8(4), pp. 19-43. 1994.

[13] Environment Agency and DEFRA The Appraisal of Human Related Intangible Impacts of Flooding. Joint DEFRA/EA R\&D technical report FD2005/TR, DEFRA/EA. 2004.

[14] Green, C. H. and Penning-Rowsell, E. C. Flooding and the Quantification of 'Intangibles'. Water and Environment Journal, 3(1), pp. 27-30. 1989.

[15] Adamson, M. Floods: causes, management and relief. The Chartered Institution of Water and Environment Management. Ireland Office of Public Works. 2003.

[16] Brouwer, R. and Pearce, D. W. Cost-Benefit Analysis and Water resources Management. Cheltenham: Edward Elgar. 2005.

[17] Hanley, N., Wright, R. and Adamowicz, V. Using Choice Experiments to Value the Environment. Environmental and Resource Economics, 11(3), pp. 413-428. 1998.

[18] Bateman, I., Carson, R., Day, B., Hanemann, W. M., Hanley, N. and Hett, T. Guidelines for the use of stated preference techniques for the valuation of preferences for non-market goods. Cheltenham: Edward Elgar. 2003.

[19] Macdonald, D. N., Murdoch, J. C. and White, H. L. Uncertain hazards, insurance, and consumer choice: evidence from housing markets. Land Economics, 63(4), pp. 361-371. 1987.

[20] Troy, A. and Romm, J. Assessing the price effects of flood hazard disclosure under the California natural hazard disclosure law. Journal of Environmental Planning and Management, 47(1). 2004. 
[21] Hamilton, M. J. Coastal landscape and the hedonic price of accommodation. Ecological Economics, (62), pp. 594-602. 2007.

[22] Day, B. Submarket identification in property markets: a hedonic housing price model for Glasgow, working paper. EDM 03-09, CSERGE, University of East Anglia. 2003.

[23] Lamond, J., Proverbs, D. and Antwi, A. Measuring the impact of flooding on UK house prices A new framework for small sample problems. Property Management, 25(4), pp. 344-359. 2007.

[24] Joseph, R., Proverbs, D., Lamond, J. and Wassell, P. An analysis of the costs of resilient reinstatement of flood affected properties: A case study of the 2009 flood event in Cockermouth. Structural Survey, 9(4), pp. 279-293. 2011.

[25] Lamond, J. E. Financial implications of flooding and the risk of flooding on households. in Lamond, J., Booth, C., Hammond, F. and Proverbs, D. (eds.) Flood Hazards: Impacts and Responses for the Built Environment. London: Taylor and Francis Group, pp. 317-326. 2012.

[26] ABI Assessment of the cost and effect on Future Claims of Installing Flood Damage Resistant Measures. Association of British Insurers: London. 2003. 